\title{
DNA damage induced by furocoumarin hydroperoxides plus UV (360 nm)
}

\author{
Bernd Epe ${ }^{1,3}$, Martin Häring1, Danaboyina Ramaiah',2, \\ Helga Stopper', Mohamed M.Abou-Elzahab², \\ Waldemar Adam ${ }^{2}$ and Chantu R.Saha-Möller ${ }^{2}$ \\ 'Instiure of Pharmacology and Toxicology and 'institute of Organic \\ Chemistry, University of Würzburg, 97078 Würzburg, Germany \\ ${ }^{3}$ To whom correspondence should be addressed at: the Institute of \\ Pharmacology and Toxicology, University of Würburg, Versbacher Str. 9. \\ 97078 Würzburg, Germany
}

When irradiated at $360 \mathrm{~nm}$, furocoumarins with a hydroperoxide group in a side chain efficiently give rise to a type of DNA damage that can best be explained by a photoinduced generation of hydroxyl radicals from the excited photosensitizers. The observed DNA damage profiles, i.e. the ratios of single-strand breaks, sites of base loss (AP sites) and base modifications sensitive to formamidopyrimidine-DNA glycosylase (FPG protein) and endonuclease III, are similar to the DNA damage profile produced by hydroxyl radicals generated by ionizing radiation or by xanthine and xanthine oxidase in the presence of Fe(III)-EDTA. No such damage is observed with the corresponding furocoumarin alcohols or in the absence of near-UV radiation. The damage caused by the photo-excited hydroperoxides is not influenced by superoxide dismutase (SOD) or catalase or by $\mathrm{D}_{2} \mathrm{O}$ as solvent. The presence of $t$-butanol, however, reduces both the formation of single-strand breaks and of base modifications sensitive to FPG protein. The cytotoxicity caused by one of the hydroperoxides in L5178Y mouse lymphoms cells is found to be dependent on the near-UV irradiation and to be much higher than that of the corresponding alcohol. Therefore the new type of photo-induced damage occurs inside cells. Intercalating photosensitizers with an attached hydroperoxide group might represent a novel and versatile class of DNA damaging agents, e.g. for phototherapy.

\section{Introduction}

Upon excitation by visible light or near-UV radiation many photosensitizers induce oxidative DNA damage, either indirectly via singlet oxygen (type II reaction) or directly via hydrogen abstraction or electron transfer (type I) reaction with DNA (1-6). The spectrum of DNA modifications generated by these reactions is very different from that induced by hydroxyl radicals. While hydroxyl radicals (e.g. generated by ionizing radiation or by superoxide in the presence of $\mathrm{Fe}$ (III)-EDTA) induce approximately equal amounts of base modifications $(7)$, singlestrand breaks and sites of base loss (AP sites), both singlet oxygen and several photosensitizers in the presence of light generate predominantly base modifications $(8-10)$. Some (or all) of the base modifications are recognized by the repair endonuclease formamidopyrimidine-DNA glycosylase (FPG protein) $(8-10)$. At least some of these FPG-sensitive base modifications have been identified as 8-hydroxyguanine (7,8-dihydro-8-oxoguanine) $(11,12)$. Photo-activated furocoumarins, in contrast to many other photosensitizers, generally induce relatively little oxidative DNA damage; rather covalent DNA adkucts are characteristic and wellstudied modifications $(13-15)$.

Recently, phthalimide hydroperoxides have been shown to generate hydroxyl radicals upon excitation by near-UV irradiation $(16,17)$. Mechanistically the reaction most probably involves a homolysis of the peroxide bond, following either an intramolecular energy transfer or an intramolecular hydrogen abstraction by the excited chromophore $(16,17)$.

Here we describe the analysis by means of specific repair endonucleases of the DNA modifications induced by photoactivated furocoumarin hydroperoxides. Our results demonstrate that the novel hydroperoxides, but not the corresponding alcohols, efficiently produce a type of DNA damage that can best be explained by photochemical generation of hydroxyl radicals from these compounds.

\section{Materials and methods}

Materials

DNA from bacteriophage PM2 (PM2 DNA) was prepared acconding to the method of Salditt $e t$ al. (18). More than $95 \%$ was in the supercoiled form, as determined by the method described below. Formamidopyrimidine-DNA glycosylase (FPG protein) (19) was obtained from Dr S.Boiteux (Villejuif, France). Endonuclease III (20) was provided by Dr R.P.Cunningham (Albany, NY). UV endonuclease was partially purified from Micrococcus huteus (21). Exonuclease III was purchased from Boehringer (Mannheim, Germany). All repair endonucleases were cested for their incision at reference modifications (i.e. thymine glycols induced by $\mathrm{OsO}_{4}$, AP sites induced by low $\mathrm{pH}$, pyrimidine dimers induced by $\mathrm{UV}^{254}$ ) under the applied assay conditions (see below) to ensure that the correct substrate modifications are fully recognized and no incision at non-substrate modifications takes place (see 8). The synthesis of the furocoumarin hydroperoxides has been described elsewhere (22). The corresponding alcohols were obtained from the hydroperoxides by reduction with triphenylphosphine. LS178Y $\left(\mathrm{tk}^{+1-}\right)$ mouse lymphoma cells were obtained from Dr W. Caspary (Research Triangle Park, NC). DNA modification

The exposure of PM2 DNA $(10 \mu \mathrm{g} / \mathrm{ml})$ to near-UV radiation $(360 \mathrm{~nm}, 4.5$ $\mathrm{kJ} / \mathrm{m}^{2}$ ) in the presence and absence of furocoumarins was carried oun on ice in phosphate buffer ( $5 \mathrm{mM} \mathrm{KH} \mathrm{PO}_{4}, 50 \mathrm{mM} \mathrm{NaCl}$, $\mathrm{pH} 7.4$ ), which contained $1 \%$ ethanol, by means of a black light lamp (Osram HQV; 5 min at $10 \mathrm{~cm}$ distance). In some of the experiments SOD $(60 \mathrm{U} / \mathrm{ml})$ or catalase $(280 \mathrm{U} / \mathrm{ml})$ was added or $\mathrm{H}_{2} \mathrm{O}$ in the buffer was replaced by $\mathrm{D}_{2} \mathrm{O}$. In the last case the $\mathrm{pD}$ of the buffer was adjusted according to Srere $a$ al. (23). The final isotope purity was greater than 96\%. The exposure to $\mathrm{NDPO}_{2}$ (disodium salt of 1,4 atheno-2,3-berrodioxin1,4-dipropanoic acid), to ionizing radiation and to xanthine in the presence of xanthine oxidase (10 units/ml) and Fe(UI) - EDTA $(100 \mu \mathrm{M})$ has been described previously (24). The DNA was precipitated by ethanol/sodium acetate and redissolved in $\mathrm{BE}_{1}$ buffer $(20 \mathrm{mM}$ Tris- $\mathrm{HCl}, \mathrm{pH} 7.5,100 \mathrm{mM} \mathrm{NaCl}, 1 \mathrm{mM}$ EDTA) for damage analysis

DNA damage analysis

A DNA relaration assay was used to quantify endomuclease-sensitive modifications and strand breaks. It makes use of the fact that supercoiled PM2 DNA is converted by either a single-strand break (SSB) or the incision of a repair endonuclease into a relaxed (nicked) form which migrates separately from the superooiled form in agarose gel electrophoresis. Quantification of both forms of DNA by fluorescence scanning allows the determination of the number of single-strand breaks per PM2 molecule ( $10^{4}$ bp). If an incubation with repair endonucleases precedes the gel electrophoresis the number of single-strand breaks plus endonuclease-sensitive sites (ESS) is obtained (equation 1) (sec 24,25).

$$
\text { SSB }+ \text { ESS }=-\ln [1.4 \times I /(1.4 \times I+I I)]
$$

where $I$ is the fluorescence of the supercoilod form and $I I$ is the fluorescence of the relaxed form. 
An aliquot of $0.3 \mu \mathrm{g}$ of the modified DNA in $20 \mu \mathrm{JB}$, buffer was incubated for $30 \mathrm{~min}$ at $37^{\circ} \mathrm{C}$ with $10 \mu \mathrm{l}$ of $\mathrm{BE}_{\mathrm{l}}$ buffer (for the determination of directly produced strand breaks) or of one of the following repair endomuclease preparations: (i) exonuclease $\mathrm{WI}, 300 \mathrm{U} / \mathrm{ml}$ in $20 \mathrm{mM}$ Tris- $\mathrm{HCl}, \mathrm{pH} 8.0,100$ mM NaCl, $15 \mathrm{mM} \mathrm{CaCl}$; (ii) FPG protein, $3 \mu \mathrm{g} / \mathrm{ml}$ in $\mathrm{BE}_{1}$ buffer; (iii) endonuclease III, $40 \mathrm{ng} / \mathrm{ml}$ in $\mathrm{BE}_{1}$ buffer; (iv) UV endonuclease, $90 \mu \mathrm{g} / \mathrm{ml}$ in $\mathrm{BE}_{15}$ buffer ( $\mathrm{BE}_{1}$ buffer containing $15 \mathrm{mM}$ EDTA). The reactions were stoppod by addition of $3 \mu$ 10\% sodium dodecyl sulphate and the DNA applied to an agarose slab electrophoresis gel. After electrophoresis and staining with chidium bromide the relative amoumts of the supercoiled and the nicked form of the DNA were determined using a fluorescence scanner (FTR20; Sigma Insonumens, Berlin) From these values the average number of single-strand breaks per DNA molocule produced either directly by the damaging agent or by the subsequent enrymatic incision at the endonuclease-sensitive modifications was calculated according to equation 1 .

Cytotaxiciry

LS178Y mouse lymphoma cells were cultured in RPMI 1640 medium containing $10 \%$ horse serum. Exposure to furocoumarins plus $\mathrm{UV}^{360}\left(4.5 \mathrm{~kJ} / \mathrm{m}^{2}\right)$ was carried out in PBSG (140 mM NaCl, $3 \mathrm{mM} \mathrm{KCl}, 8 \mathrm{mM} \mathrm{Na} \mathrm{HPO}_{4}, 1 \mathrm{mM}$ $\mathrm{KH}_{2} \mathrm{PO}_{4}, 1 \mathrm{mM} \mathrm{CaCl}, 0.5 \mathrm{mM} \mathrm{MgCl}, 0.1 \%$ glucose, $\mathrm{pH} 7.4$ ) on ice in a shallow dish $\left(10^{6} \mathrm{cells} / \mathrm{ml}\right)$. The cells were pelleted by centrifugation and resuspended in full medium $\left(5 \times 10^{4}\right.$ cells $\left./ \mathrm{ml}\right)$. The proliferation of the cells at $37^{\circ} \mathrm{C}$ was measured for $70 \mathrm{~h}$.

\section{Results}

Photo-activated furocoumarin hydroperoxides, but not the corresponding alcohols, efficiently induce various types of axidative DNA modifications

Supercoiled DNA from bacteriophage PM2 (104 bp) was exposed in phosphate buffer at $0^{\circ} \mathrm{C}$ to near-UV irradiation $(360$ $\mathrm{nm}, 4500 \mathrm{~J} / \mathrm{m}^{2}$ ) in the presence of various concentrations of the furocoumarin hydroperoxides $1 \mathrm{a}-4 \mathrm{a}$ or the corresponding alcohols $1 \mathrm{~b}$ and $4 \mathrm{~b}$ (Figure 1). Subsequently the DNA was analysed for the following types of modification: (i) DNA singleand double-strand breaks; (ii) sites of base loss (AP sites) recognized by exonuclease III from $E$.coli; (iii) base modifications plus AP sites sensitive to the UV endonuclease from M.luteus; (iv) base modifications plus AP sites sensitive to the endonuclease III from E.coli; and (v) base modifications plus AP sites sensitive to formamidopyrimidine-DNA glycosylase (FPG protein) from

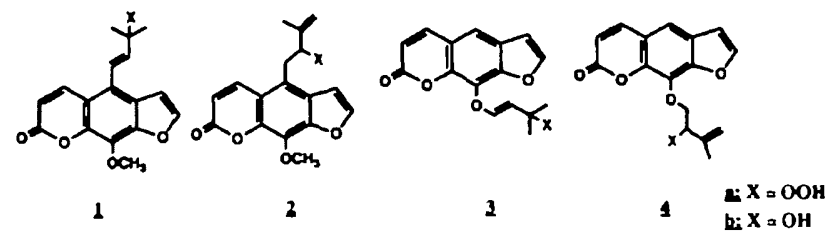

Fig. 1. Chemical structures of the furocoumarins $1-4$ used in this study.
E.coli. The recognition spectrum of the enzymes is summarized in Table I.

As shown in Figure 2, upon photo-excitation all furocoumarin hydroperoxides induce DNA modifications in amounts which increase linearly with the concentration. From the slopes of the best-fit straight lines the numbers of modifications induced per concentration unit were calculated (Table II). Without near-UV irradiation no modifications were observed, even at the highest peroxide concentration that was soluble $(\sim 500 \mu \mathrm{M}$; data not shown). Only very low levels of oxidative damage were observed with furocoumarins $1 \mathrm{~b}$ and $4 \mathrm{~b}$, in which the hydroperoxide group is replaced by a hydroxyl group, even at high concentrations (Figure 2, Table II).

All furocoumarin hydroperoxides tested induced both singlestrand breaks and AP sites (detected by exonuclease III) (Figure 2, Table II). The UV endonuclease does not recognize significantly more modifications than exonuclease III. Therefore all UV endonuclease-sensitive sites are also AP sites and pyrimidine dimers are virtually absent. The numbers of modifications sensitive to endonuclease III and, in particular, FPG protein are significantly higher than the number of AP sites recognized by exonuclease III or UV endonuclease. This indicates the presence of base modifications sensitive to these first two enzymes. Currently available data indicate that endonuclease III specifically recognizes oxidation products of pyrimidines, in particular 5,6-dihydropyrimidine derivatives $(26-28)$. The only base modifications known at present to be recognized by FPG protein are imidazole ring-opened purines (formamidopyrimidines) and 8-hydroxyguanine (7,8-dihydro-8-oxoguanine) (12). The number of double-strand breaks induced by the photoactivated furocoumarin hydroperoxides in PM2 DNA is very low and might arise from independently generated, closely opposed single-strand breaks (Table II).

At equimolar concentration the most active furocoumarin la produces 20 to 80 -fold more DNA modifications than does furocoumarin $4 \mathrm{a}$ (Table II). The different potencies cannot be ascribed to the different absorptions of the furocoumarin derivatives at $360 \mathrm{~nm}$, since these vary only by a factor of two (Table II).

The DNA damage profile induced by furocoumarin hydroperoxides is similar to the damage profile characteristic for hydraxyl radicals

In Figure 3 the relative amounts of the various types of modifications induced by photo-activated furocoumarin hydroperoxides are depicted in the form of DNA damage profiles. For comparison, DNA damage profiles are shown which were observed after treatment of PM2 DNA with: (a) singlet oxygen,

Table I. Recognition spectrum of the repair endonucleases used in this study

\begin{tabular}{|c|c|c|c|c|}
\hline \multirow[t]{2}{*}{ Repair endonuclease } & \multicolumn{3}{|c|}{ Sites of base loss (AP sites) } & \multirow[t]{2}{*}{ Base modifications } \\
\hline & Regularb & 1'Oxidation ${ }^{c}$ & 4-Oxidation ${ }^{d}$ & \\
\hline FPG protein & + & - & + & 8-Hydroxyguanine, formamidopyrimidines \\
\hline Endonuclease III & + & - & + & 5,6-Dihydropyrimidine derivatives \\
\hline UV endonuclease & + & - & + & Cyclobutane pyrimidine phocodimers \\
\hline Exonuclease III & + & + & $(+)^{e}$ & \\
\hline
\end{tabular}

As identified to date (for reviews, soe 26-29).

Unmodified desoxyribose moiety.

'Desoxyribose oxidized in the 1' position.

'Desoxyribose oxidized in the 4' position.

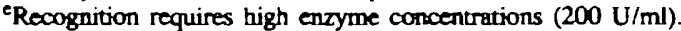


generated by thermal decomposition of the endoperoxide $\mathrm{NDPO}_{2}$ (30); (b) hydroxyl radicals, generated by xanthine and xanthine oxidase in the presence of Fe(III)-EDTA; and (c) hydroxyl radicals, generated by ionizing radiation. These latter damage profiles have been described previously $(8-10)$.

The damage profiles (Figure 3 ) indicate that the ratios of the various types of modifications induced by furocoumarins la and $2 a$ are similar to the damage induced by hydroxyl radicals, generated either by xanthine plus xanthine oxidase in the presence of Fe(III) - EDTA (Fenton reaction) or by ionizing radiation. The damage profiles produced by $3 a$ and, even more so, by $4 a$ differ in a higher relative yield of FPG-sensitive base modifications compared to single-strand breaks and therefore are more closely related to damage profiles induced by singlet oxygen (Figure 3), which is also characteristic for many photosensitizers absorbing visible light (9).

Singlet oxygen, superaxide and hydrogen peraxide are not involved in the DNA damage by photo-activated furocoumarin hydroperaxides

To test for a possible role of superoxide, hydrogen peroxide or singlet oxygen in the generation of FPG-sensitive base modifications and single-strand breaks by photo-activated furocoumarins $3 \mathrm{a}$ and $4 \mathrm{a}$ the near-UV irradiation was carried out in the presence of SOD or catalase or the $\mathrm{H}_{2} \mathrm{O}$ in the buffer was replaced by $\mathrm{D}_{2} \mathrm{O}$. For comparison, the effects of these modifiers on the DNA damage by $\mathrm{NDPO}_{2}$ (generation of singlet oxygen) and ionizing radiation (generation of hydroxyl radicals) were tested in parallel.
The results (Table III) indicate that neither SOD nor catalase have a significant effect on the damage produced by the four agents. Therefore superoxide and hydrogen peroxide (and a subsequent Fenton reaction of these species) are not inolved in the damage formation. The formation of FPG-sensitive base modifications by chemically generated singlet oxygen (decomposition of $\mathrm{NDPO}_{2}$ ) is increased approximately 10 -fold in $\mathrm{D}_{2} \mathrm{O}$ (Table III), in accordance with the 10 -fold longer lifetime of singlet oxygen in this solvent $(31,32)$. In contrast, the solvent change has no effect on the formation of single-strand breaks and FPG-sensitive base modifications by ionizing radiation or by the photo-activated furocoumarin hydroperoxides (Table III).

The DNA damage by photo-activated furocoumarin hydroperaxides is reduced in the presence of $t$-butanol

$t$-Butanol is an efficient scavenger of hydroxyl radicals. The effect of various t-butanol concentrations on the formation of singlestrand breaks and FPG-sensitive base modifications by the photoactivated furocoumarin hydroperoxides $1 \mathrm{a}$ and $4 \mathrm{a}$ and by ionizing radiation is shown in Figure 4.

The yields of single-strand breaks and of modifications sensitive to FPG protein are both reduced in the presence of t-butanol, both in the case of the photo-activated hydroperoxides and ionizing radiation, however, the inhibition in the case of the hydroperoxides is less pronounced. Moreover, in the damage produced by hydroperoxide 4a the FPG-sensitive modifications are less affected than the single-strand breaks. t-Butanol does not inhibit the formation of base modifications by $\mathrm{NDPO}_{2}$ (24).
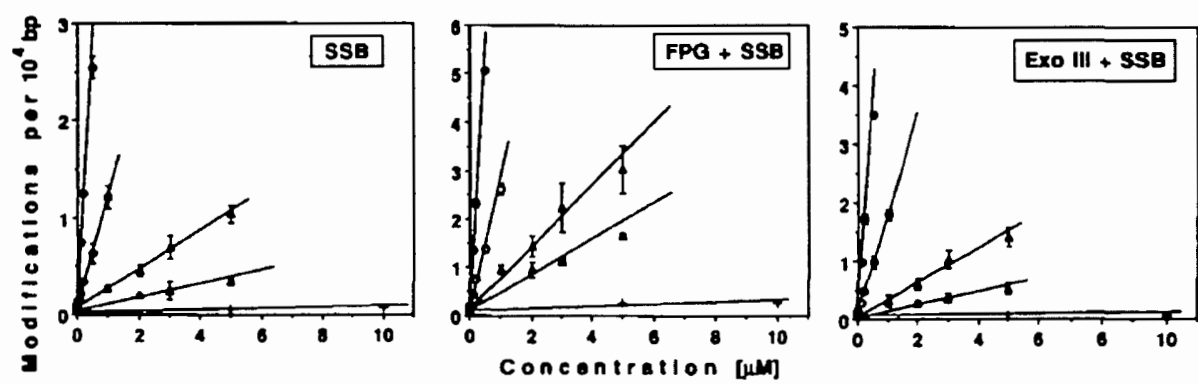

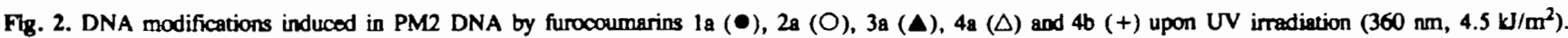
Left: DNA single-strand breaks; center: sum of single-strand breaks plus sites sensitive to FPG protein; right: sum of single-strand breaks plus sites sensitive to exonuclease III. Background values at zero concentration give the number of modifications present in urmodified DNA plus those induced by the UV irradiation alone.

Table II. Endonuclease-sensitive modifications and strand breaks induced in PM2 DNA by furocoumarins la-4a upon irradiation by UV 360 (4.5 $\mathrm{kJ} / \mathrm{m}^{2}$ )

\begin{tabular}{|c|c|c|c|c|c|c|c|}
\hline \multirow[t]{2}{*}{ Furocoumarin } & \multirow[t]{2}{*}{$\epsilon^{*}$} & \multicolumn{6}{|c|}{ Modifications $(\text { per } \mu \mathrm{M})^{b}$} \\
\hline & & FPG $^{c}$ & Endo III $^{d}$ & UV endor & Exo III $f$ & SSBB & $\mathrm{DSB}^{\mathrm{h}}$ \\
\hline $1 \mathrm{a}$ & 2530 & $4.9 \pm 0.6$ & $3.1 \pm 0.6$ & $2.3 \pm 0.6$ & $1.8 \pm 0.6$ & $4.8 \pm 0.3$ & $0.020 \pm 0.002$ \\
\hline $2 a$ & 2250 & $1.30 \pm 0.08$ & $0.88 \pm 0.05$ & $0.55 \pm 0.04$ & $0.58 \pm 0.06$ & $1.11 \pm 0.02$ & $0.005 \pm 0.001$ \\
\hline $3 a$ & 1580 & $0.38 \pm 0.06$ & $0.13 \pm 0.04$ & $0.05 \pm 0.05$ & $0.09 \pm 0.03$ & $0.19 \pm 0.01$ & $n d^{i}$ \\
\hline 48 & 1350 & $0.24 \pm 0.03$ & $0.06 \pm 0.01$ & $0.010 \pm 0.004$ & $0.03 \pm 0.01$ & $0.060 \pm 0.003$ & nd \\
\hline lb & 2600 & $(2 \pm 8) \times 10^{-5}$ & $(1.4 \pm 1) \times 10^{-5}$ & $(7 \pm 5) \times 10^{-5}$ & $(-3 \pm 3) \times 10^{-5}$ & $(5 \pm 4) \times 10^{-5}$ & nd \\
\hline $4 b$ & 1460 & $(6.6 \pm 0.6) \times 10^{-4}$ & $(3 \pm 1) \times 10^{-4}$ & $(2.4 \pm 0.8) \times 10^{-4}$ & $(5.6 \pm 1.0) \times 10^{-4}$ & $(0.6 \pm 0.6) \times 10^{-4}$ & nd \\
\hline
\end{tabular}

${ }^{2}$ Molar absorption coefficient $[\mathrm{l} / \mathrm{mol} / \mathrm{cm}]$ at $360 \mathrm{~nm}$.

${ }^{6}$ Number of modifications $\left( \pm S D\right.$ ) per $10^{4}$ bp calculated by linear regression from the data points shown in Figure 2.

$c-$ Modifications sensitive to FPG protein, endonuclease III, UV endonuclease preparation from $M$. Iuteus, endonuclease IV and exonuclease III, respectively.

sSingle-strand breaks.

'Double-strand breaks.

Not determined. 


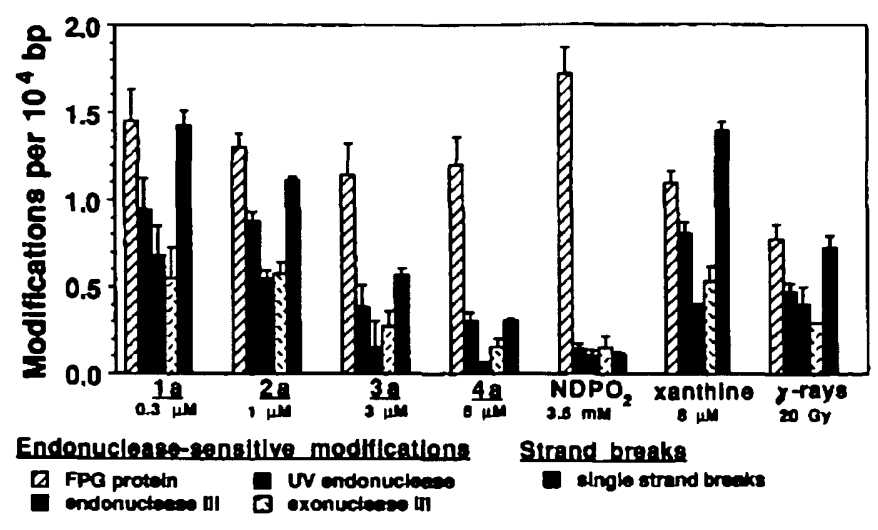

Fig. 3. DNA damage profiles. Single-strand breaks and various endonuclease-sensitive modifications induced in PMQ DNA by treatrnent with (i-iv) furocoumarins $1 \mathrm{a}-4 \mathrm{a}$ plus $\mathrm{UV}^{360}\left(4.5 \mathrm{~kJ} / \mathrm{m}^{2}\right)$; (v) $\mathrm{NDPO}_{2}$ in $\mathrm{D}_{2} \mathrm{O}$ buffer $\left(3.5 \mathrm{mM}, 2 \mathrm{~h}, 37^{\circ} \mathrm{C}\right.$ ); (vi) xanthine $(8 \mu \mathrm{M})$ in the presence of xanthine oxidase and Fe(III)-EDTA (30 min, $20^{\circ} \mathrm{C}$ ); and (vii) ionizing radiation (20 Gy at $50 \mu \mathrm{g} / \mathrm{ml}$ DNA).

Table III. Effects of $\mathrm{D}_{2} \mathrm{O}$, SOD and catalase on the DNA damage induced by photo-activated furocoumarins $3 \mathrm{a}$ and $4 \mathrm{a}$, ionizing radiation and singlet oxygen chemically generated from $\mathrm{NDPO}_{2}$

\begin{tabular}{|c|c|c|c|c|}
\hline \multirow[t]{2}{*}{ Damaging agent } & \multirow[t]{2}{*}{$\begin{array}{l}\text { Damage } \\
\text { type }\end{array}$} & \multicolumn{3}{|c|}{$\begin{array}{l}\text { Relative extent of damage }(\%) \text { in the } \\
\text { presence of }{ }^{b, c}\end{array}$} \\
\hline & & $\mathrm{D}_{2} \mathrm{O}$ & $\begin{array}{l}\text { SOD } \\
(20 \mu g / \mathrm{ml})\end{array}$ & $\begin{array}{l}\text { Catalase } \\
(315 \mathrm{U} / \mathrm{ml})\end{array}$ \\
\hline \multirow[t]{2}{*}{ Furocoumarin 3} & SSB & $97 \pm 20$ & $102 \pm 14$ & $98 \pm 17$ \\
\hline & FPG & $91 \pm 7$ & $83 \pm 11$ & $90 \pm 5$ \\
\hline \multirow[t]{2}{*}{ Furocoumarin 4} & SSB & $78 \pm 8$ & $105 \pm 6$ & $78 \pm 12$ \\
\hline & FPG & $87 \pm 10$ & $83 \pm 3$ & $88 \pm 10$ \\
\hline \multirow{2}{*}{ Ionizing radiation } & SSB & $107 \pm 12$ & $87 \pm 21$ & $91 \pm 6$ \\
\hline & FPG & $92 \pm 12$ & $71 \pm 7$ & $97 \pm 5$ \\
\hline $\mathrm{NDPO}_{2}$ & FPG & $960 \pm 190$ & $105 \pm 12$ & $99 \pm 2$ \\
\hline
\end{tabular}

SSB, single-strand breaks; FPG, modifications sensitive to FPG protein. Number of modifications observed in the absence of modifier defined as $100 \%$.

'Dats are means of two or three independent experiments ( \pm SD).
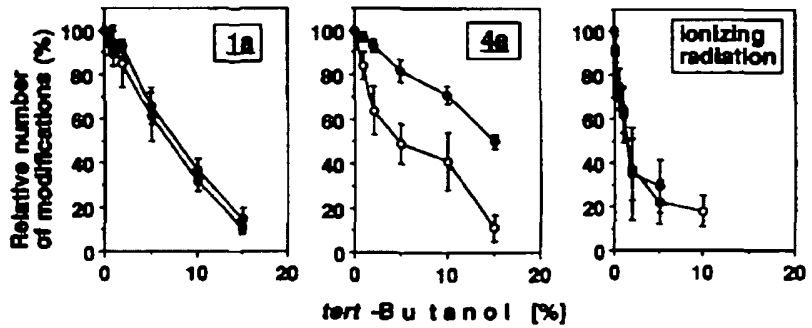

Fig. 4. Inhibition by $t$-butanol of the generacion of single-strand breaks $(O)$ and modifications sensitive to FPG protein ( $)$ by furocoumarins la and $4 a$ phus $\mathrm{UV}^{360}\left(4.5 \mathrm{~kJ} / \mathrm{m}^{2}\right)$ and by ionizing radiation. Damage induced in the absence of tbutanol assumed as $100 \%$. Data points represent means of $2-3$ independent experiments.

The cytotoxicity of furocoumarin hydroperoxide la depends on the hydroperaride group

LS178Y mouse lymphoma cells were exposed to furocoumarins $1 \mathrm{a}$ and $\mathrm{lb}$ with and without near-UV irradiation $(360 \mathrm{~nm})$. After removal of the photosensitizer the proliferation of the treated cells in full medium was observed.

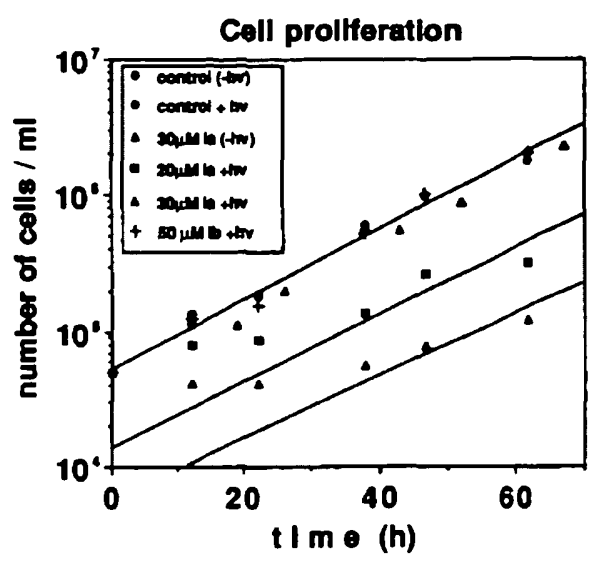

Fig. 5. Growth of LS178Y cells treated on ise in the absence (open symbols) or presence (closed symbols) of $\mathrm{UV}^{360}\left(4.5 \mathrm{~kJ} / \mathrm{m}^{2}\right)$ with furocoumarin hydroperoxide la $(\square 20 \mu \mathrm{M} ; \Delta, \Delta 30 \mu \mathrm{M})$, the corresponding alcohol $1 \mathrm{~b}(+50 \mu \mathrm{M})$ or in the absence of furocoumarin $(O, 0$ controls). In all cases the photosensitizer was removed by centrifugation directly after treatment and the cells were resuspended in full medium at $37^{\circ} \mathrm{C}$

The results shown in Figure 5 indicate that hydroperoxide la at concentrations of 20 and $30 \mu \mathrm{M}$ gives rise to a dose-dependent reduction in the number of proliferating cells upon near-UV irradiation. No cytotoxicity is observed under the same conditions in the absence of near-UV. In contrast, the corresponding alcohol lb is non-toxic, even at $50 \mu \mathrm{M}$, with and without near-UV irradiation. The cytotoxicity of la therefore requires both photoexcitation of the furocoumarin chromophore and the presence of the hydroperoxide moiety.

\section{Discussion}

The results presented above indicate that the DNA-damaging properties of photo-excited furocoumarins are strongly influenced by a hydroperoxide group in a side chain of the aromatic ring system. Upon near-UV irradiation the furocoumarin hydroperoxides give rise very efficiently to DNA strand breaks, AP sites and oxidative base modifications sensitive to endonuclease III and FPG protein, while only very low levels of these modifications are generated by derivatives which lack the hydroperoxide moiety. The following kinds of evidence indicate that the damage produced by the hydroperoxides is caused by a photo-induced generation of hydroxyl radicals. (i) The damage profiles, i.e. the ratios of the various types of DNA modifications generated, are similar to the damage profiles induced by agents that generate hydroxyl radicals, but are very different from the damage profile induced by singlet oxygen (Figure 3). The latter type of damage profile has been observed with several photosensitizers which absorb visible light, e.g. riboflavin, acridine orange and methylene blue, which modify DNA either via singlet oxygen (type II reaction) or by direct electron transfer or hydrogen abstraction (type I reaction) $(6,9)$. (ii) Singlet oxygen, hydrogen peroxide and superoxide are not involved in the damage formation, since the number of modifications is not influenced by $\mathrm{D}_{2} \mathrm{O}$ as solvent, catalase or SOD (Table III). (iii) The formation of both strand breaks and FPG-sensitive modifications (8-hydroxyguanine, formamidopyrimidines, AP sites) is efficiently inhibited by t-butanol, a known scavenger of hydroxyl radicals (Figure 4). (iv) Near-UV radiation is necessary for the DNA damage formation.

Mechanistically the generation of hydroxyl radicals from photo- 
excited furocoumarin hydroperoxides might involve an intramolecular triplet - triplet energy transfer from the excited furocoumarin chromophore to the peroxide moiety, followed by homolytic scission of the peroxide (equation 2, path a). This type of mechanism has also been proposed to explain some of the products generated from photo-excited phthalimide hydroperoxides $(16,17)$. A prerequisite for efficient energy transfer is that the triplet energy of the furocoumarin chromophore [for 8-methoxypsoralen $\sim 63 \mathrm{kcal} / \mathrm{mol}$ (33)] is higher than that of the hydroperoxide moiety. That this is indeed the case is supported by the finding that the homolysis of $\alpha$-ketohydroperoxides can be triggered by photo-excited fluorenone [triplet energy $53 \mathrm{kcal} / \mathrm{mol}$ (34)]. Alternatively, intramolecular electron transfer from the excited furocoumarin chromophore to the hydroperoxide moiety would generate a hydroxyl radical and a chromophore radical cation linked to an alkoxy anion (equation 2 , path b). Charge annihilation through intramolecular electron back-transfer would then produce the same products as the energy transfer reaction.

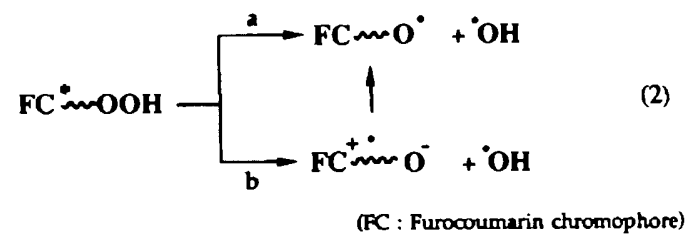

In the case of furocoumarin hydroperoxide $4 a$, which has the lowest DNA-damaging potential of the four hydroperoxides tested, it is likely that hydroxyl radicals are not responsible for all of the FPG-sensitive base modifications, since these are less affected by the presence of $t$-butanol than are the single-strand breaks (Figure 4). Moreover, the relative number of FPGsensitive modifications is $\sim 3$-fold higher than in the type of damage ascribed to hydroxyl radicals (Figure 3). Both findings can be explained by the assumption that in the case of furocoumarin $4 a \sim 60 \%$ of the FPG-sensitive modifications are generated via a direct electron transfer or hydrogen abstraction (type I) reaction with DNA, which is not affected by t-butanol and yields only few strand breaks and AP sites. The formation of FPG-sensitive modifications (8-hydroxyguanine) by type I reactions has been demonstrated recently $(35-37)$. The small extent of DNA damage caused by the corresponding alcohol $4 \mathrm{~b}$ then indicates that the hydroperoxide moiety is also important for this damaging mechanism. Presumably the hydroperoxide moiety facilitates the oxidation of the intermediate guanine radical cation generated in the type I reaction (equation 3). A similar mechanism has been suggested previously for the formation of FPG-sensitive base modifications by 1,2-dioxetanes (35).

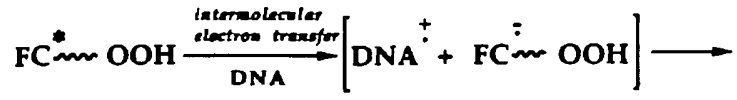

$$
\begin{aligned}
& {\left[\mathrm{DNA} \mathbf{A}^{+}+\mathrm{FC} \sim \mathrm{O}^{-}+\mathrm{OH}\right] \longrightarrow \underset{\text { base modifications }}{\text { FPG }: \text { Furocoumurin chromophore) }}}
\end{aligned}
$$

Base modifications sensitive to FPG protein at a level comparable to that of covalent adduct formation have recently been observed after exposure of DNA to 3-carbethoxypsoralen plus near-UV radiation (38), in confirmation of earlier reports on the oxidative damage produced by this furocoumarin (39). Similar modifications were not observed with 8-methoxypsoralen or 5-methoxypsoralen (37). In contrast to the hydroxyl radicalmediated damage described here, the oxidative DNA damage produced by 3-carbethoxypsoralen is most probably generated via singlet oxygen and/or direct electron transfer (type I reaction), since both the number of strand breaks and the number of AP sites is relatively low and the damage is increased in $D_{2} O$ as solvent (38). The absolute number of FPG-sensitive modifications generated by furocoumarin hydroperoxide la per unit UV dose and unit concentration is approximately two orders of magnitude higher than that generated by 3-carbethoxypsoralen. This fact probably reflects the much higher oxidative reactivity of hydroxyl radicals than of singlet oxygen, in addition to possible differences in the quantum yields of hydroxyl radical and singlet oxygen formation.

The observation that the DNA damage induced by the photoexcited furocoumarin hydroperoxides is less efficiently inhibited by t-butanol than is that induced by ionizing radiation (Figure 4) indicates that in the former case the generation of hydroxyl radicals takes place directly at the DNA (from furocoumarin molecules covalently or non-covalently bound to the DNA), so that a reaction of the hydroxyl radicals with DNA is favoured compared to that with $t$-butanol. Further studies will demonstrate whether such a target-directed formation of hydroxyl radicals indeed takes place and gives rise to sequence-specific DNA damage. Preliminary experiments indicate that both furocoumarins 1 and 4 form covalent adducts upon near-UV irradiation (data not shown).

The observation that hydroperoxide $1 \mathrm{a}$ is much more phototoxic to mammalian cells than the corresponding alcohol $\mathrm{lb}$ (Figure 5) gives evidence that hydroxyl radical formation is relevant under cellular conditions. Interestingly, in the case of furocoumarin 4 , however, the hydroperoxide $4 \mathrm{a}$ and the corresponding alcohol $4 \mathrm{~b}$ are equally phototoxic (data not shown). Therefore the relative importance of the new type of photo-induced damage and other mechanisms such as DNA interstrand cross-linking and type I photo-oxidation depends on the chemical structure. A possible interplay between the various types of DNA damage and the relevance of damage to other cellular targets remains to be established.

The results suggest that it could be rewarding to develop intercalating photosensitizers with an attached hydroperoxide group as a novel and versatile class of DNA-damaging agents, e.g. for phototherapy.

\section{Acknowledgements}

We thank S.Boiteux for providing FPG protein and R.P.Cunningham for endonuclease 111. This work was supported by the Deutsche Forschungsgemeinschaft (SFB 172) and by the Wilhelm Sander-Stiftung. D.R. (1992-1993) and M.M.A. (1990-1991) are Alexander von Humbold Postdoctoral Fellows.

\section{References}

1. Foote,C.S. (1968) Mechanisms of photosensitized oxidation. Science, 162, $963-970$.

2. Piette,J., Mervilie-Louis,M.-P. and Decuyper,J. (1986) Damages induced in mucleic acids by photosensitization. Photochem. Photobial., 44, 793-802.

3. Kochevar,I.E., (1987) Mechanisms of drug photosensitization. Photochem. Photobiol., 45, 891-895.

4. Kochevar,I.E. and Dunn,D.A. (1990) Photosensitized reactions of DNA: cleavage and addition. In Morrison,M. (ed.), Bioorganic Photachemistry, Vol. 1. John Wiley and Sons, New York, pp. 273-316.

5. Cadet.J. and Vigny,P. (1990) The photochemistry of nucleic acids. In Morrison, H. (ad.), Bioorganic Phosochemisrry, Vol. 1. John Wiley and Sons, New York, pp. 1-272. 
6. Epe,B. (1993) DNA damage induced by photosensitization. In Halliwell,B and Aruoms,O. (ods), DNA and Free Radicals. Ellis Horwood, Chichester, pp. $41-65$.

7. Aruoma, O.I., Halliwell,B. and Dizdaroglu,M. (1989) Iron ion dependent modifications of bases in DNA by the superoxide radical generating system hypoxanthine/ranthine oxidase. J. Biol. Chem., 264, 13024-13028.

8. Müller,E., Boiteux,S., Cunningham,R.P. and Epe,B. (1990) Enzymatic recognition of DNA modifications induced by singlet oxygen and photosensitizers. Nucleic Acids Res., 18, 5969-5973.

9. Epe,B., Pflaum,M. and Boiteux,S. (1993) DNA damage induced by photosensitizers in cellular and cell-free systems. Mutot. Res., 299, 135- 145

10. Epe,B., Pflaum,M., Häring, M., Hegler.J. and Rodiger,H. (1993) Use of repair endomucleases to characterize DNA damage induced by reactive axygen species in cellular and cell-free systems. Taxicol. Len., 67, 57-72.

11. Schneider J.E., Price,S., Maidt,M.L., Gutteridge J.M.C and Floyd,R.A (1990) Methylene blue plus light mediates 8-hydroxy-2'-deoxyguanosine formation in DNA preferentially over strand breakage. Nucleic Acids Res. 18. $631-635$.

12. Boitcux,S., Gajewski,E., Laval,J. and Dizdaroglu,M. (1992) Substrate specificity of the Escherichia coli Fpg protein (formamidopyrimidine-DNA glyoosylase): excision of purine lesions in DNA produced by ionizing radiation or photosensitization. Biochemistry, 31, $106-110$.

13. Gasparro,F.P. (1988) Psoralen DNA Photobiology. CRC Press, Boca Raton, FL, Vols 1 \& 2 .

14. Averbeck,D. (1989) Recent advances in psoralen phototoxicity mechanism. Photochem. Photobiol., 6, 859-882.

15. CadetJ., Vigny,P. and Midden,W.R. (1990) Photoreactions of furocoumarins with biomolecules. J. Photochem. Photobiol. B, 6, 197-206.

16. Saito,I., Takayama,M. and Matsuura, T. (1990) Phthalimide hydroperoxides as efficient photochemical bydroxyl radical generators. A noved DNA-cleaving agent. J. Am. Chem. Sac., 112, 883-884.

17. Matsugo,S. and Saito,1. (1991) Photochemical cleavage of $N$ (bydroperoxyalkyl)phthalimides by intramolecular energy transfer. Tetrahedron Lett., 32, 2949-2950.

18. Saldit, M., Braunstein,S.N., Camerini-Otero,R.D. and Frandin,R.M. (1972) Structure and synthesis of a lipid-containing bacteriophage. Virology, 48, 259-262.

19. Boiteux,S., O'Connor, T.R., Loderer,F., Gouryette,A. and Laval,J. (1990) Homogenous Escherichia coli FPG protein. J. Biol Chem., 265, 3916-3922.

20. Asahara,H., Wistort,P.M., Bank,J.F., Bakerian,R.H. and Cunningham,R.P. (1989) Purification and characterization of Escherichia coli endomuclease III from the cloned nth gere. Biochemistry, 28, 4444-4449.

21. Riazzudin,S. (1980) Purification and properties of pyrimidine dimer specific endonucleases from Micrococcus lureus. In Grossman.L. and Moldave, $K$. (ods), Methods in Enzymology, Vol. 65. Academic Press, New York, pp. 185-191.

22. Abou-Elzahab,M., Adam,W. and Saha-Moller,C.R. (1991) Photooxygenation of some potentially skin-photosensitizing furocoumarins: imperatorin, alloimperatorin and its methyl ether and acetate derivatives. Liebigs Ann. Chem., $967-970$.

23. Srere,P.A., Kosicki,G.W. and Lumry,R. (1961) Isotope rate effects with $\mathrm{D}_{2} \mathrm{O}$ in several enzyme systems. Biachim Biophys. Acta, 50, 184-185.

24. Epe,B., Mftzel,P. and Adam,W. (1988) DNA damage by oxygen radicals and excited state species: a comparative study using enrymatic probes in vitro. Chem-Biol. Interactions, 67, 149-165.

25. Epe,B., Hegler,J. and Wild,D. (1989) Singlet oxygen as an ultimately reactive species in Salmonella typhimurium DNA damage induced by methylene blue/visible light. Cancinogenesis, 10, 2019-2024.

26. Wallace,S.S. (1988) AP endonucleases and DNA glycosylases that recognize oxidative DNA damage. Environ. MoL Mutagen., 12, 431-477.

27. Lindahl, T. (1990) Repair of intrinsic DNA lesions. Mutat. Res., 238, $305-311$.

28. Doetsch,P.W. and Cunningham,R.P. (1990) The enzymology of apurinic/apyrimidinic endonucleases. Mutat. Res., 236, 173-201.

29. Povirk,L.F. and Steighner,R. (1989) Oxidized apurinic/apyrimidinic sites formed in DNA by oxidative mutagens. Mutar. Res., 214, 13-22.

30. Di Mascio,P. and Sies,H. (1989) Quantification of singlet oxygen generated by thermolysis of 3,3'-(1,4-naphthylidene)dipropionate. Monomol and dimol phocoemission and the effects of 1,4-diazabicyclo[2.2.2]octane. J. Am. Ohem. Soc., 111, 2909-2914

31. Merkel,P.B., Nilsson,R. and Keams,D.R. (1972) Deuterium effects on singlet oxygen lifectimes in solutions. A new test of singlet oxygen reactions. J. Am. Chem. Soc., 94, 1030-1031.

32. Rodgers,M.A.J. and Snowden,P.T. (1982) Lifetime of $\mathrm{O}_{2}\left({ }^{1} \Delta_{g}\right)$ in liquid water as determined by time-resolved luminescence measurements. $J$. Am. Chem. Sac., 104, 5541-5543.

33. Bensasson,R.V., Land,E.J. and Salet,C. (1978) Triplet excited state of furocoumarins: reaction with mucleic acids bases and amino acids. Photochem. Photobiol., 27, 273-280.

34. Sawaki,Y. and Ogata, Y. (1976) Photolysis of $\alpha$-hydroperoxyketones. J. Am. Chem. Soc., 91, 7324-7327.

35. Epe,B., Müller,E., Adam,W. and Saha-Möller,C.R. (1992) Photochemical DNA modifications induced by 1,2-dioxetanes. Chem.-Biol. Interactions, 85, $265-281$.

36. Kasai,H., Yamaizami,Z., Berger,M. and Cadea,J. (1992) Photosensitized formarion of 7,8-dihydro-8-axo-2' deoxygranosine (8-hydroxy-2'-deoxyguanosine in DNA by riboflavin: a non single oxygen mediated reaction. J. Am. Chem. Soc., 114, $9692-9694$.

37. Epe, B., Henzl, H. Adam,W and Saha-Moller,C.R. (1993) Endonucleasesensitive DNA modifications induced by acetone and acetophenone as photosensitizers. Nucleic Acids Res., 21, 863-869.

38. Boiteux,S., Yeung,A.T. and Sage,E. (1993) Enzymatic recognition and biological effects of the DNA damage incuced by 3-carbethoxypsoralen plus UVA. Mutat. Res, 294, 43-50.

39. Sage,E., Le Doan, T., Boyer,V., Helland,D.E., Kiuler,L., Helene,C. and Moustacchi,E. (1989) Oxidative DNA damage photo-induced by 3-carbethoxypsoralea and other furocoumarins. Mechanisms of photo-oxidation and recognition by repair enzymes. J. Mol. Biol., 209, 297-314.

Received on May 28, 1993; revised on July 1, 1993; accepied on A ugust 4, 1993 